\title{
Signalling pathways involved in the cooperative effects of ovine and murine GDF9 + BMP15-stimulated thymidine uptake by rat granulosa cells
}

\author{
Karen L Reader ${ }^{1}$, Derek A Heath ${ }^{1}$, Stan Lun ${ }^{1}$, C Joy McIntosh ${ }^{1}$, Andrea H Western ${ }^{1}$, \\ Roger P Littlejohn ${ }^{2}$, Kenneth P McNatty ${ }^{3}$ and Jennifer L Juengel ${ }^{1}$ \\ ${ }^{1}$ AgResearch, Reproductive Biology and ${ }^{2}$ Bioinformatics, Mathematics and Statistics, Invermay Agricultural Centre, \\ Private Bag 50034, Mosgiel 9053, New Zealand and ${ }^{3}$ School of Biological Sciences, Victoria University of \\ Wellington, PO Box 600, Wellington 6140, New Zealand
}

Correspondence should be addressed to J L Juengel; Email: jenny.juengel@agresearch.co.nz

D A Heath and C J McIntosh are now at School of Biological Sciences, Victoria University of Wellington, Wellington, New Zealand. $\mathrm{S}$ Lun is now at Mesynthes Ltd, Lower Hutt, Wellington, New Zealand.

A H Western is now at Arotec Diagnostics Ltd, Petone, Wellington, New Zealand.

\begin{abstract}
Growth differentiation factor 9 (GDF9) and bone morphogenetic protein 15 (BMP15) are oocyte-secreted factors known to be involved in regulating the proliferation and differentiation of granulosa cells during follicular growth. The aims of this study were to determine the signalling pathways used by recombinant forms of murine and ovine GDF9 and BMP15 in combination (GDF9+BMP15) and the molecular complexes formed by combinations of these factors. Differences in the molecular forms of combinations of murine and ovine GDF9+ BMP15 were observed by western blot analysis. Ovine GDF9+ BMP15-stimulated ${ }^{3} \mathrm{H}$-thymidine uptake was completely blocked by SMAD2/3 and nuclear factor- $\kappa B$ pathway inhibitors and partially blocked by a p38-mitogen-activated protein kinase (MAPK) inhibitor. Thymidine uptake by murine GDF9+BMP15 was reduced by the SMAD2/3 and extracellular signal-regulated kinase-MAPK pathway inhibitors and increased after addition of a $\mathrm{C}$-Jun $\mathrm{N}$-terminal kinase inhibitor. Stimulation of ${ }^{3} \mathrm{H}$-thymidine uptake by GDF9+ BMP15 from either species was not affected by the SMAD1/5/8 pathway inhibitor. In conclusion, both murine and ovine GDF9+ BMP15-stimulated thymidine incorporation in rat granulosa cells was dependent on the SMAD2/3 signalling pathway but not the SMAD1/5/8 pathway. Divergence in the non-SMAD signalling pathways used by murine and ovine GDF9+ BMP15 was also evident and may be due to the differences observed in the molecular complexes formed by these factors. These results are consistent with the hypothesis that the disparate cooperative functions of GDF9 and BMP15 in different species are mediated by divergent non-SMAD signalling pathways.

Reproduction (2011) 142 123-131
\end{abstract}

\section{Introduction}

Growth differentiation factor 9 (GDF9) and bone morphogenetic protein 15 (BMP15) are oocyte-secreted factors that are members of the transforming growth factor $\beta$ (TGFB) superfamily. They are known to play an essential role in regulating ovarian follicular development and ovulation rate in several species and have different functions depending on the species of origin of both the granulosa cells and the growth factor (Moore et al. 2004, Shimasaki et al. 2004, McNatty et al. 2005a,b). The different phenotypes exhibited by mice and sheep with inactivating mutations in GDF9 or $B M P 15$ are further evidence of species differences in the actions of these factors. Mice lacking active BMP15 apparently have only minor changes in follicular growth
(Yan et al. 2001), whereas sheep homozygous for inactivating mutations in BMP15 exhibit primary ovarian failure (Galloway et al. 2000). Both mice and sheep with inactivated GDF9 are infertile (Dong et al. 1996, Hanrahan et al. 2004).

GDF9 signalling has been shown to be mediated by the type I receptor TGFBR1 and the type II receptor BMPR2 to activate the SMAD2/3 pathway (Vitt et al. 2002, Kaivo-Oja et al. 2003, Mazerbourg et al. 2004). BMP15 has been shown to activate the SMAD1/5/8 pathway, co-immunoprecipitate with BMPR1B and its interaction with granulosa cells can be blocked by the extracellular domain (ECD) of BMPR2 (Moore et al. 2003). Protein and/or mRNA for each of these receptors have been shown to be expressed in sheep, rat and mouse granulosa cells, apart from TGFBR1 in the rat 
whereby mRNA was shown to be present in whole ovary tissue (Yi et al. 2001, Erickson \& Shimasaki 2003, Gueripel et al. 2004, Gilchrist et al. 2006, Feary et al. 2007, Rosairo et al. 2008). Rat granulosa cells exhibit increased proliferation in response to TGFB (Dorrington et al. 1988), which would imply that the TGFBR1 receptor is present in rat granulosa cells. It is likely that several second messenger pathways, other than the SMAD pathways, are also involved in the transduction of signal from receptor complexes activated by both GDF9 and BMP15. Stimulation of granulosa cell mitoses by human BMP15 can be suppressed by inhibition of the extracellular signal-regulated kinase-mitogen-activated protein kinase (ERK-MAPK) pathway (Moore et al. 2003). There is evidence that TGFB signalling acts via the p38-MAPK signalling pathway (Sano et al. 1999, Compton et al. 2006) but not the c-Jun N-terminal kinase (JNK) pathway (Sano et al. 1999), although other reports suggest that the JNK pathway is important in TGFB signalling (Atfi et al. 1997). BMP2 and BMP4 activate the nuclear factor- $\mathrm{KB}$ (NFKB) pathway and this activation can be inhibited by the peptide SN50 (Mohan et al. 1998).

GDF9 and BMP15 are co-expressed in the oocyte during follicular development and have been shown to have much greater biological activity when acting cooperatively than individually. For example, there was no effect on rat granulosa cell ${ }^{3} \mathrm{H}$-thymidine incorporation when ovine or murine GDF9 at $25 \mathrm{ng} / \mathrm{ml}$ and ovine or murine BMP15 at $6 \mathrm{ng} / \mathrm{ml}$ were individually added. However, when GDF9 and BMP15 were added in combination (GDF9+BMP15) at these doses, a sevenfold increase in thymidine uptake was observed (McIntosh et al. 2008). In studies where the concentrations of either GDF9 or BMP15 were serially diluted while the other factor remained constant, the stimulation of ${ }^{3} \mathrm{H}$-thymidine incorporation was dose dependent (McNatty et al. 2005a). The cooperative effects of GDF9 and BMP15 on ${ }^{3} \mathrm{H}$-thymidine uptake by granulosa cells were blocked by the ECD of BMPR2 and by the TGFBR1/ ACVR1B/ACVR1C-SMAD2/3 inhibitor SB431542 (Edwards et al. 2008, Mclntosh et al. 2008), although none of the type I receptor ECDs tested had any effect (Edwards et al. 2008). It is not known whether the SMAD1/5/8 signalling pathway or any other non-SMAD pathways are involved in the cooperative signalling of GDF9+BMP15. Therefore, further investigation into the involvement of the SMAD1/5/8, ERK-MAPK, p38-MAPK, JNK and NFKB pathways in downstream signalling from BMP15 + GDF9 activity is warranted.

The molecular mechanisms involved in the synergistic effects of GDF9 and BMP15 are poorly understood, complicated by these growth factors potentially interacting with receptors either as monomers or as noncovalently associated homodimers or heterodimers, and in differently processed forms. Recombinant BMP15 and GDF9 are secreted as mixtures of cleaved mature and proregion proteins and unprocessed promature protein. After cross-linking both murine and ovine recombinant GDF9 were mainly present as dimers and high-molecular weight multimers, with only a small amount of monomer observed (Edwards et al. 2008, McIntosh et al. 2008). In contrast BMP15 of both species were present as monomers or multimers with no evidence of a dimeric mature form. When murine GDF9 and BMP15 or ovine GDF9 and BMP15 were combined and cross-linked, mature proteins were found in large multimeric complexes. The proregions of both murine proteins were also present in these complexes; however, it is not yet known in which molecular complexes the ovine GDF9 and BMP15 proregions exist. No direct evidence for either murine or ovine mature region heterodimers has been obtained but, in the mouse, the BMP15 proregion co-immunoprecipitated with GDF9 mature protein indicating a heteromeric association between BMP15 and GDF9 (Mclntosh et al. 2008). In the same study, a murine BMP15 proregion antibody was able to immunoneutralise murine GDF9+BMP15-stimulated ${ }^{3} \mathrm{H}$-thymidine incorporation in rat granulosa cells, providing further evidence that the BMP15 proregion plays a role in the cooperative bioactivity of GDF9 with BMP15.

The primary objective of this study was to determine whether inhibition of the SMAD1/5/8 or other non-SMAD signalling pathways altered the level of ${ }^{3} \mathrm{H}$-thymidine incorporation by granulosa cells when stimulated with different combinations of ovine and murine GDF9+BMP15. Rat granulosa cells were chosen as they produce $\geq$ fourfold increases in response to GDF9+BMP15 in the ${ }^{3} \mathrm{H}$-thymidine uptake assay (McNatty et al. 2005a, Edwards et al. 2008, McIntosh et al. 2008), have been well validated for this type of assay (Vitt et al. 2000, Saragueta et al. 2002) and because higher yields of granulosa cells can be obtained with fewer animals compared with mice. Ovine granulosa cells were not considered because GDF9+BMP15 only stimulated $\sim 1.5$-fold increases in ${ }^{3} \mathrm{H}$-thymidine uptake in these cells (McNatty et al. 2005b) making it difficult to observe changes in response to signalling pathway inhibitors. Within- and cross-species combinations of murine and ovine GDF9+BMP15 were examined by western blot analysis to determine whether species differences in the physiological functions and downstream signalling could be due to differences in the molecular complexes.

\section{Results \\ Molecular forms of combinations of murine and ovine GDF9 and BMP15}

After cross-linking combined conditioned media, murine and ovine GDF9 mature region dimers were detected, as well as high-molecular weight bands that were noticeably larger for murine than ovine 
A

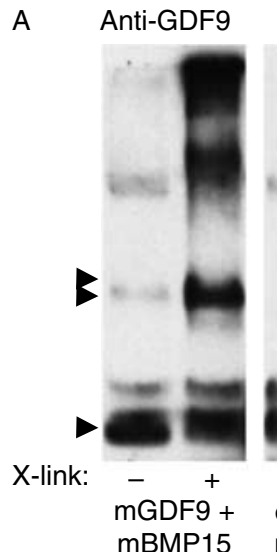

B

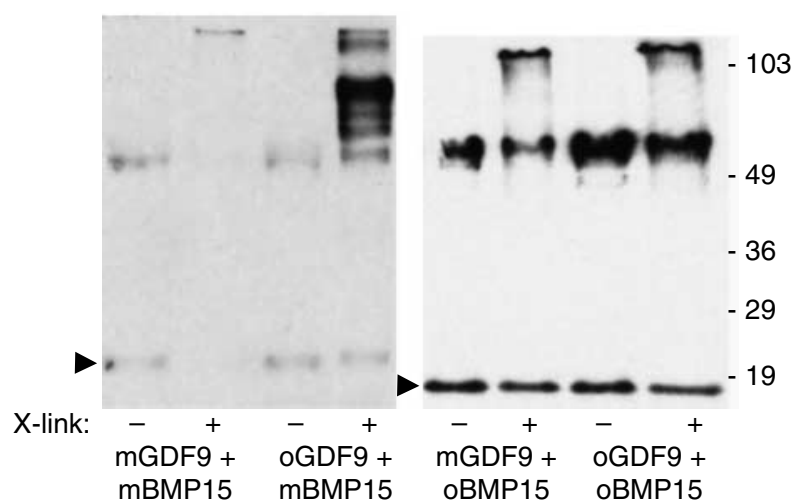

Figure 1 Western blots showing detection of molecular forms of ovine (o) and murine $(\mathrm{m})$ GDF9+BMP15 in combination, with and without chemical cross-linking. GDF9 was present at $25 \mathrm{ng} / \mathrm{ml}$ and BMP15 at $6 \mathrm{ng} / \mathrm{ml}$. The location of molecular weight markers are shown on the right hand side. Single arrowheads indicate location of monomers, whereas double arrowheads show the dimers. (A) Detection of GDF9 with mab37A. Each panel is from the same gel but different exposure times were used for murine GDF9 (10 min) and ovine GDF9 (30 s). (B) Detection of murine BMP15 with mab3A-A and ovine BMP15 with mab61A. Each panel represents a different gel.

GDF9 (Fig. 1A). Additionally, a different pattern of band intensity was observed for GDF9 interactions, whereby cross-linked ovine GDF9 and ovine BMP15 formed less dimer and more multimer than ovine GDF9 with murine BMP15 (Fig. 1A). When murine BMP15 was mixed with murine GDF9, all of the mature band of BMP15 cross-linked and disappeared (Fig. 1B). In contrast, murine BMP15 with ovine GDF9 remained as a monomer and also formed high-molecular weight complexes as did ovine BMP15 mixed with murine or ovine GDF9 (Fig. 1B).

\section{Effect of pathway inhibitors on ${ }^{3} \mathrm{H}$-thymidine incorporation stimulated by GDF9+BMP15, activin A, BMP4 and FCS}

As expected, treatment with ovine or murine GDF9+ BMP15, activin A, BMP4 and FCS stimulated $(P<0.001)$
${ }^{3} \mathrm{H}$-thymidine incorporation in rat granulosa cells relative to the $293 \mathrm{H}$ control (Fig. 2).

Treatment with the inhibitor to the SMAD2/3 signalling pathway reduced by $\sim 50 \%{ }^{3} \mathrm{H}$-thymidine incorporation stimulated by BMP4 and FCS, which was similar to the effect observed with the $293 \mathrm{H}$ control media (Fig. 3) and the inhibitor alone (results not shown). However, this pathway inhibitor completely prevented the stimulation of ${ }^{3} \mathrm{H}$-thymidine uptake by ovine GDF9+BMP15 and inhibited murine GDF9+BMP15 and activin A stimulation by $80 \%$ (all $P<0.001$ when compared with $293 \mathrm{H}$ control with inhibitor). The SMAD1/5/8 pathway inhibitor partially blocked $(P<0.001)$ the effects of BMP4 stimulated ${ }^{3} \mathrm{H}$-thymidine uptake but had no effect with any other treatment (Fig. 3).

Addition of the NFKB pathway inhibitor blocked ovine GDF9+BMP15 $(P<0.001)$, increased the effect of FCS $(P<0.01)$ but had no effect on $293 \mathrm{H}$, activin A, BMP4 and murine GDF9+BMP15 stimulated ${ }^{3} \mathrm{H}$-thymidine uptake (Fig. 3). The JNK pathway inhibitor caused a 2.4-fold increase $(P<0.001)$ in thymidine incorporation when cultured with murine GDF9+ BMP15 but had no significant effect on any other treatment (Fig. 3).

Treatment with the p38-MAPK pathway inhibitor caused a $40 \%$ reduction in thymidine incorporation with activin A, BMP4, FCS and ovine GDF9+BMP15 $(P<0.01)$ but had no significant effect on either $293 \mathrm{H}$ control or murine GDF9+BMP15 (Fig. 3). The ERK-MAPK inhibitor strongly suppressed $(P<0.001)$ ${ }^{3} \mathrm{H}$-thymidine uptake for all treatments including the $293 \mathrm{H}$ control. However, the suppression of activin A, BMP4 and murine GDF9+BMP15 was significantly greater than for $293 \mathrm{H}(P<0.05,0.05,0.01$ respectively), although the effect with FCS and ovine GDF9+BMP15 was similar to the $293 \mathrm{H}$ control (Fig. 3). This suppression of thymidine uptake was not related to cell death as cells maintained $>85 \%$ viability when treated with the ERK-MAPK inhibitor U0126 at $5 \mu \mathrm{M}$ concentration for $24 \mathrm{~h}$ (CellTitre 96 Aqueous One, In Vitro Technologies, Auckland, New Zealand; $n=2$ pools, results not shown).

\section{Effect of NFKB and JNK pathway inhibitors on ${ }^{3} \mathrm{H}$-thymidine incorporation stimulated by combinations of murine and ovine GDF9+BMP15}

To determine whether GDF9, BMP15 or both factors from each species were working through the NFKB and JNK signalling pathways, within- and cross-species combinations of these factors were cultured with these inhibitors in the ${ }^{3} \mathrm{H}$-thymidine rat granulosa cell bioassay. Murine GDF9 with murine BMP15, murine GDF9 with ovine BMP15, ovine GDF9 with murine BMP15 and ovine GDF9 with ovine BMP15 stimulated 4.7-, 1.4-, 6.0- and 3.9-fold increases $(P<0.001)$ in thymidine incorporation, respectively, when compared 


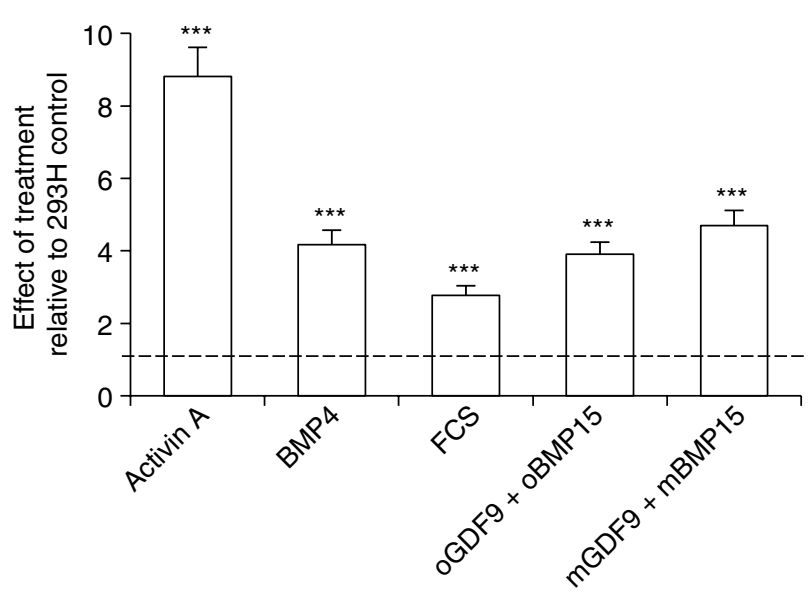

Figure 2 The effects of addition of activin A (10 ng/ml), BMP4 $(30 \mathrm{ng} / \mathrm{ml})$, FCS (5\% v/v), ovine (o) GDF9 + BMP15 (25 and $6 \mathrm{ng} / \mathrm{ml}$ respectively) and murine (m) GDF9+BMP15 (25 and $6 \mathrm{ng} / \mathrm{ml}$ respectively) on ${ }^{3} \mathrm{H}$-thymidine incorporation by rat granulosa cells. Values represent mean \pm S.E.M. relative to $293 \mathrm{H}$ control (set at 1.0, dashed line). $* * * P<0.001$ compared with $293 \mathrm{H}$ control.

with the $293 \mathrm{H}$ control media. The NFKB pathway inhibitor significantly reduced $(P<0.001)$ thymidine uptake stimulated by ovine GDF9 with either murine or ovine BMP15 (Fig. 4). However, the NFKB pathway inhibitor had no effect on thymidine uptake stimulated by murine GDF9 with either murine or ovine BMP15. As previously observed, addition of the JNK pathway inhibitor increased thymidine incorporation in cells treated with murine GDF9 and murine BMP15 2.4-fold $(P<0.001)$ but had no effect on cells treated with ovine GDF9 and ovine BMP15. Thymidine incorporation stimulated by murine GDF9 with ovine BMP15 increased 1.6-fold $(P<0.05)$ with the addition of the JNK pathway inhibitor. This effect was significantly lower than that observed with murine GDF9 and murine BMP15 $(P<0.05)$. Thymidine uptake stimulated by ovine GDF9 with murine BMP15 was inhibited $(P<0.05)$ by $30 \%$ (Fig. 4) but was not significantly different to the effect observed when the JNK inhibitor was cultured with ovine GDF9 and ovine BMP15.

\section{Discussion}

Previous work has identified the essential role of the BMPR2 and TGFBR1/ACVR1B/ACVR1C-SMAD2/3 signalling pathway in the cooperative stimulation of thymidine uptake by murine and ovine GDF9+BMP15 (Edwards et al. 2008, Mclntosh et al. 2008). The present results support the role of the SMAD2/3-mediated pathway in GDF9+BMP15 signalling. Given that BMP15 has been shown to act through BMPR1B to stimulate SMAD1/5/8 (Moore et al. 2003), it seemed reasonable to assume that the cooperative actions of GDF9+BMP15 on thymidine incorporation would also involve this pathway. However, inhibition of
SMAD1/5/8-mediated signalling had no affect on either murine or ovine GDF9+BMP15-stimulated thymidine incorporation. As the inhibitor partially blocked the effects of BMP4, which is known to signal via BMPR1B (Shimasaki et al. 2004), it would appear that BMPR1B (or ACVR1 and BMPR1A)-mediated signalling via SMAD1/5/8 is not required for the cooperative effects of GDF9 + BMP1 5 on ${ }^{3} \mathrm{H}$-thymidine uptake. BMP15 has recently been shown to inhibit the SMAD1/5/8 pathway during early Xenopus embryogenesis (Di Pasquale \& Brivanlou 2009). However, if BMP15 is also able to inhibit this pathway in rat granulosa cells, it is unlikely that this is the cause of the increased ${ }^{3} \mathrm{H}$-thymidine uptake as inhibition of the SMAD1/5/8 pathway had no effect on thymidine incorporation in $293 \mathrm{H}$ controltreated cells. Given that BMP4-stimulated ${ }^{3} \mathrm{H}$-thymidine incorporation is, in part, dependent on the activation of the BMPR1B pathway in granulosa cells, it would also seem unlikely that inhibition of this pathway could be critical for increased proliferation in rat granulosa cells.

In this study, the NFKB pathway was shown to be essential for the stimulation of ${ }^{3} \mathrm{H}$-thymidine uptake by ovine GDF9 with either ovine or murine BMP15 but not murine GDF9 with either species of BMP15, or any of the other treatments tested. Other TGFB superfamily
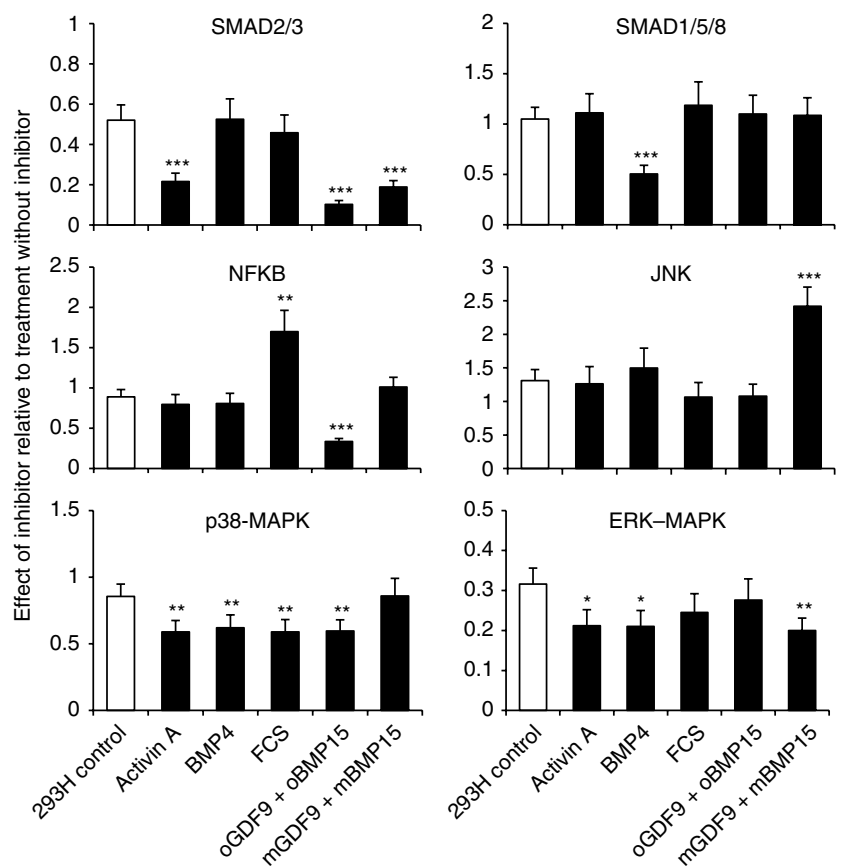

Figure 3 The effects of addition of $293 \mathrm{H}$-conditioned control media $(8.5 \% \mathrm{v} / \mathrm{v})$, activin A $(10 \mathrm{ng} / \mathrm{ml}), \mathrm{BMP} 4(30 \mathrm{ng} / \mathrm{ml}), \mathrm{FCS}(5 \% \mathrm{v} / \mathrm{v})$, ovine (o) GDF9 + BMP15 (25 and $6 \mathrm{ng} / \mathrm{ml}$ respectively) and murine (m) GDF9+BMP15 (25 and $6 \mathrm{ng} / \mathrm{ml}$ respectively) with inhibitors to the signalling pathways SMAD2/3, SMAD1/5/8, NFKB, JNK, p38-MAPK and ERK-MAPK on ${ }^{3} \mathrm{H}$-thymidine incorporation by rat granulosa cells. Values represent mean \pm S.E.M. relative to treatment without inhibitor. ${ }^{*} P<0.05$; ${ }^{* *} P<0.01$; ${ }^{* * *} P<0.001$ compared with $293 \mathrm{H}$ control with inhibitor. 


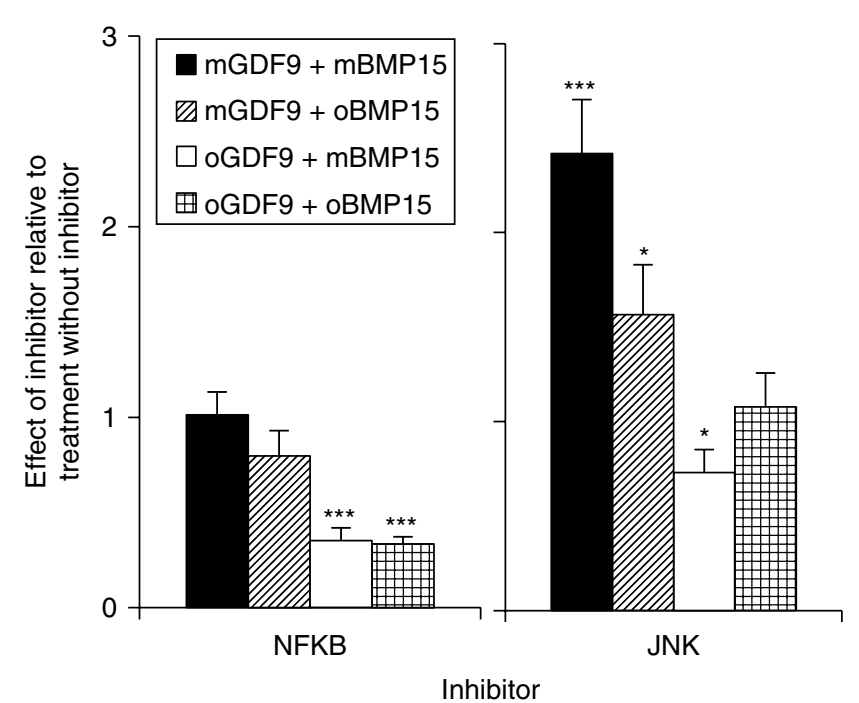

Figure 4 The effects of combinations of ovine (o) and murine (m) GDF9+BMP15 with inhibitors to the NFKB and JNK signalling pathways on ${ }^{3} \mathrm{H}$-thymidine incorporation by rat granulosa cells. Both ovine and murine GDF9 were at $25 \mathrm{ng} / \mathrm{ml}$ and both ovine and murine BMP15 at $6 \mathrm{ng} / \mathrm{ml}$. Values represent mean \pm S.E.M. relative to GDF9+BMP15 treatment without inhibitor. ${ }^{*} P<0.05 ;{ }^{* * *} P<0.001$ compared with treatment without inhibitor.

members have been reported to activate the NFKB pathway. For example, BMP2 and BMP4 increased NFKB activation in corneal fibroblast cells and the addition of the NFKB inhibitor SN50 with BMP2 and BMP4 stimulated apoptosis (Mohan et al. 1998). AMH has also been shown to induce NFKB signalling in breast and prostate cancer cells albeit to suppress proliferation and activate apoptosis (Hoshiya et al. 2003), although this does not occur in all cell types responsive to $\mathrm{AMH}$ (Belville et al. 2005). TGFB2, which binds to TGFBR1, has also been shown to activate NFKB (Lu \& Stark 2004). Interestingly, in this tumour model with PC3 prostate cancer cells, latent TGFB is found to activate NFKB without activating the SMAD pathway, leading to tumour progression. Latent TGFB is composed of three components, namely, a homodimer of the mature protein non-covalently linked to homodimers of the $\mathrm{N}$-terminal proregion of the protein that is covalently linked to a latent TGFB binding protein (Oklu \& Hesketh 2000). The recent finding that both murine GDF9 and BMP15 form high-molecular weight complexes containing the proregions of both proteins indicates the possibility that similar latent-type complexes could be formed (Mclntosh et al. 2008). Given the use of conditioned media from HEK-293H cells transfected with ovine GDF9 or BMP15 in the current experiment, the role of an analogous latent form of GDF9+BMP15 cannot be discounted. Clearly, through whatever form(s) of ovine GDF9+BMP15 that stimulate proliferation of rat granulosa cells, activation of the NFKB pathway is critical.

Activation of the JNK pathway has been shown to be either pro- or anti-apoptotic depending on the duration of activation, the cell type and the activity of other signalling pathways (Anning 2003). The increase in proliferation caused by the addition of the JNK inhibitor to murine GDF9+BMP15 suggests that these factors may cause JNK-stimulated apoptosis in granulosa cells. Treatment with JNK inhibitor alone did not increase thymidine incorporation in control cells, but in this case, the JNK pathway may not have been activated and consequently apoptosis had not been stimulated. Further experiments would be required to confirm whether activation of the JNK pathway by murine GDF9 + BMP15 stimulates apoptosis in granulosa cells.

When examining the effects of suppressing the NFKB or JNK pathways on different combinations of ovine and murine GDF9 + BMP15, the effect of the NFKB inhibitor was observed only when ovine GDF9 was present. Thus, it seems likely that the activation of the NFKB pathway occurs through the actions of ovine GDF9. The differing effects of the JNK inhibitor were not clearly linked to either GDF9 or BMP15 and thus both growth factors, or their interactions, may be necessary for activation of this pathway.

Suppression of the p38-MAPK pathway inhibited, to some degree, thymidine incorporation following stimulation by ovine GDF9 + BMP15 but did not affect murine GDF9+BMP15-stimulated thymidine incorporation. The p38-MAPK pathway has also been shown to be activated in TGFB1-stimulated proliferation of hamster granulosa cells (Yang \& Roy 2006). Given that both TGFB1 and GDF9 are believed to signal through the TGFBR1-SMAD2/3 pathway, a common mechanism may be activated by ovine GDF9 and TGFB1. In contrast, murine GDF9 + BMP15-stimulated thymidine incorporation did not appear reliant on the p38-MAPK pathway even though murine GDF9 appears to act through the SMAD2/3 pathway (Gilchrist et al. 2006).

Species differences also appeared when examining the effects of the ERK-MAPK pathway, although interpretation of the data is complicated by the strong effect of the inhibitor on untreated and $293 \mathrm{H}$ controltreated cells. However, the effect of this pathway inhibitor was greater when the cells were treated with murine GDF9+BMP15 than with $293 \mathrm{H}$ or ovine GDF9+BMP15. The ERK-MAPK pathway has previously been shown to be involved in the stimulation of thymidine incorporation by human BMP15 (Moore et al. 2003) using the same inhibitor, U0126, as used in this study earlier. This suggests that the signalling by human BMP15 may be more similar to that of murine BMP15 than ovine BMP15. However, in the human BMP15 study, the inhibitor had no effect on basal levels of thymidine incorporation at $3 \mu \mathrm{M}$ (Moore et al. 2003). This is in contrast to this study where thymidine incorporation was inhibited by U0126 at concentrations between 0.3 and $5 \mu \mathrm{M}$ when cultured with $293 \mathrm{H}$ control media or ovine GDF9+BMP15, and at $5 \mu \mathrm{M}$ with all other treatments 
including the inhibitor alone. The treatment of the rats prior to cell culture and the culture conditions differed between the two experiments, and this may account for the differing results obtained.

The consistent, strongly suppressive effect of the ERKMAPK inhibitor for all the stimulators tested in this study indicates that this pathway may be generically important for granulosa cell proliferation. It has been reported that ERK activity increased during the proliferative phase of follicular growth and down-regulation of ERK activity was associated with apoptosis in rat granulosa cells (Peter \& Dhanasekaran 2003). However, in the current study with the ERK-MAPK inhibitor, no evidence of cell death was noted over the time frame and concentrations investigated.

It is not known whether the non-SMAD signalling pathways are activated either directly after binding of GDF9+BMP15 to the BMPR2 type I receptor complex or indirectly via the downstream release of other ligands, and further studies are required to elucidate this. These factors could potentially be binding to some as yet unidentified receptor. The intracellular signalling pathway activated by BMP2 has been shown to be dependent upon the method by which BMP2 complexes with the type I and II receptors. When BMP2 bound to preformed receptor complexes, it initiated the canonical SMAD pathway, while binding first to the type I receptor, followed by recruitment of the type II receptor, activated the MAPK pathway (Sieber et al. 2009).

Cross-linking experiments in this study indicate that species differences occur in the molecular interactions between GDF9 and BMP15. When murine BMP15 was combined with murine GDF9, the conformation changes appear to have obscured the epitope recognised by the anti-BMP15, mab3A-A antibody. However, when murine BMP15 was combined with ovine GDF9, the epitope seems to have been more exposed to the antibody producing a much stronger multimeric band after cross-linking. Differences were also observed with ovine GDF9 forming a different pattern of banding when combined with ovine BMP15 compared with murine BMP15. Species differences between the molecular weights of the murine and ovine GDF9 multimers were also apparent. Such differences in the molecular complexes may alter binding to the receptor complex and could potentially be the mechanism by which different second messenger signalling pathways are activated. An antibody produced against a region of the GDF9 mature domain that was fully conserved between mice and sheep was able to completely inhibit the cooperative bioactivity of ovine GDF9 with either murine or ovine BMP15 but only halved the response of murine GDF9 with either murine or ovine BMP15 (Mclntosh et al. 2008). This was despite the fact that the antibody was shown to completely block rat granulosa cell ${ }^{3} \mathrm{H}$-thymidine incorporation stimulated by murine GDF9 on its own. This further supports the notion that there may be species differences in the molecular interactions between GDF9 and BMP15. The mature regions of murine and ovine GDF9 and murine and ovine BMP15 share $\sim 90 \%$ amino acid homology; however, the proregions of murine and ovine GDF9 are only $57 \%$ homologous and those of murine and ovine BMP15 only $62 \%$ homologous. Another possible way in which GDF9 and BMP15 from different species could activate different signalling pathways may be via the presentation of the mature proteins to the target cell by the proregion(s) of BMP15 and/or GDF9. Immunoneutralisation of murine BMP15 proregion was able to inhibit the bioactivity of murine GDF9+BMP15, although a murine GDF9 proregion antibody had no effect (McIntosh et al. 2008). This suggests that the BMP15 proregion is involved in controlling the bioactivity of GDF9 and BMP15 together.

Other growth factors present in the unpurified HEK$293 \mathrm{H}$ cell expression media could be interacting with the cell signalling pathways activated by GDF9+ BMP15. However, species differences in the signalling pathways used by these growth factors were observed despite the fact that all treatments contained the same concentration of $293 \mathrm{H}$-conditioned media. The conditioned media contains multiple secreted forms of GDF9 or BMP15 protein including the pro-, pro-matureand mature-regions, and multimers of these (Mclntosh et al. 2008). This allows for the possible formation of latent-type complexes and also for the potential involvement of the pro-region in the signalling process as proposed by Mclntosh et al. (2008) which could not occur if purified preparations of the mature region of the protein were used.

In summary, the cooperative actions of GDF9+ BMP15 on thymidine incorporation by rat granulosa cells were shown to be inhibited by the suppression of the SMAD2/3 but not the SMAD1/5/8 pathways (Fig. 5). Other non-SMAD signalling pathways were also shown to be important in mediating the cooperative effects of GDF9+BMP15. Surprisingly, however, the species of the growth factors determined which of the pathways were important (Fig. 5). The NFKB pathway was essential for the cooperative effects of ovine GDF9+ BMP15, with activation of the p38-MAPK pathway perhaps also playing a role. In contrast, the NFKB pathway was not important for the actions of murine GDF9+BMP15 and the ERK-MAPK pathway was the only other pathway identified that may be involved in the stimulation of proliferation by murine GDF9+BMP15 (Fig. 5). Differences in the molecular complexes formed by murine and ovine GDF9+BMP15 may underpin the divergence in the non-SMAD signalling pathways used. Therefore, species differences in the roles of GDF9 and BMP15 may be well mediated by variations in the molecular complexes formed and subsequent activation of divergent non-SMAD signalling pathways. 


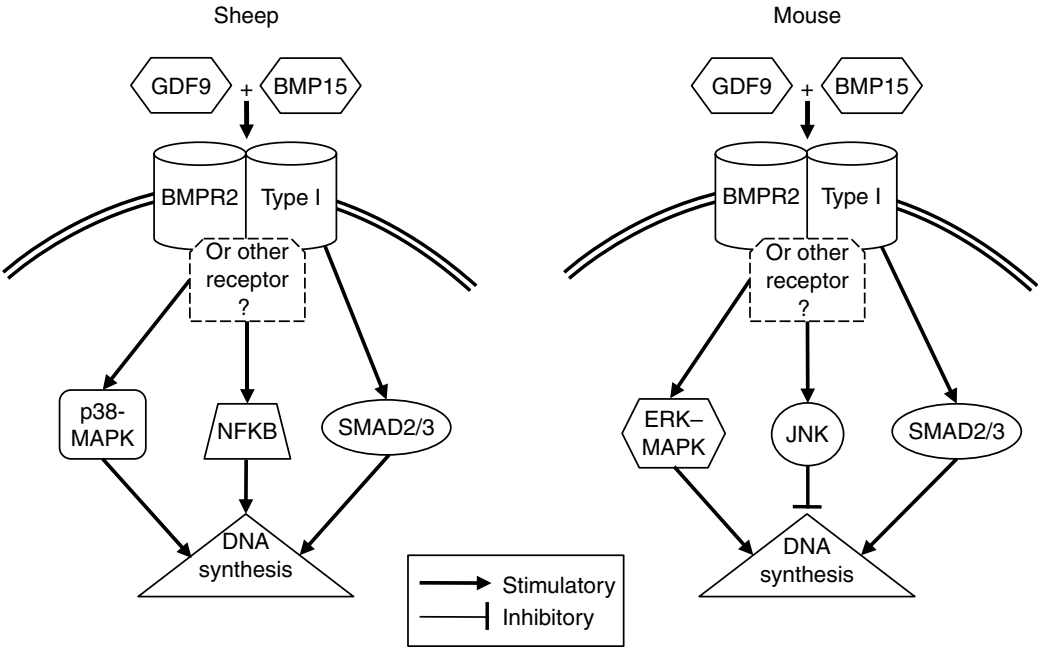

Figure 5 Summary of the signalling pathways involved in stimulation of granulosa cell proliferation by either ovine or murine GDF9+BMP15 in combination. The SMAD2/3 pathway activation is mediated by the BMPR2 receptor and either of the type I receptors; TGFBR1, ACVR1B or ACVR1C. The non-SMAD signalling pathways could be activated by this receptor complex, an unknown receptor/s or via downstream release of other ligands.
Further work is needed to determine whether these signalling pathways are specific to the regulation of DNA synthesis or whether they are also involved in other granulosa cell functions such as steroid production.

\section{Materials and Methods}

\section{Collection and preparation of granulosa cells for determination of ${ }^{3} \mathrm{H}$-thymidine incorporation}

All animal protocols were carried out in accordance with the 1999 Animal Welfare Act (Part 6) of New Zealand and were approved by the Invermay Animal Ethics Committee. For each assay, ovaries were collected from six immature 21 - to 24 dayold Sprague-Dawley rats at $46 \mathrm{~h}$ after an intra-peritoneal administration of $20 \mathrm{IU}$ equine chorionic gonadotropin (Intervet Ltd, Auckland, New Zealand). Extraneous tissue was dissected from the ovaries that were washed in Leibovitz L-15 media (Invitrogen) containing $0.1 \%$ (w/v) BSA (Sigma), $100 \mathrm{U} / \mathrm{ml}$ penicillin and $100 \mu \mathrm{g} / \mathrm{ml}$ streptomycin (Invitrogen). All visible antral follicles were punctured with a 20-gauge needle and the granulosa cells were suspended in Leibovitz L-15 media. Oocyte-cumulus complexes, isolated oocytes and follicular debris were removed with the aid of a dissecting microscope and glass pipette. The remaining granulosa cells were centrifuged at $300 \mathrm{~g}$ for $5 \mathrm{~min}$ at room temperature, washed twice in Leibovitz L-15 media and then finally re-suspended in medium-199 (Earle's; Sigma) supplemented with $2 \mathrm{mM}$ GlutaMAX-I (Invitrogen), $100 \mathrm{U} / \mathrm{ml}$ penicillin, $100 \mu \mathrm{g} / \mathrm{ml}$ streptomycin, $0.23 \mathrm{mM}$ sodium pyruvate (Sigma) and $0.3 \mathrm{mg} / \mathrm{ml}$ polyvinyl alcohol (Sigma). Granulosa cell number and viability were determined using a haemocytometer and trypan blue exclusion. Cells (20 000 viable cells/well) were cultured in a total volume of $125 \mu \mathrm{l}$ supplemented medium-199 with the treatments described below and incubated at $37{ }^{\circ} \mathrm{C}$ with $5 \% \mathrm{CO}_{2}$ in air. After $18 \mathrm{~h}$, $0.4 \mu \mathrm{Ci}$ methyl- ${ }^{3} \mathrm{H}$-thymidine (Amersham, GE Healthcare) was added to each well and the cells were incubated for further $6 \mathrm{~h}$. Following incubation, the cells were harvested with a Tomtec Harvester 96 (New Zealand Scientific, Auckland, New
Zealand) onto a filtermat and the incorporated ${ }^{3} \mathrm{H}$-thymidine determined using a Wallac Trilux MicroBeta 1450 liquid scintillation counter (New Zealand Scientific).

\section{Treatments}

The treatments included conditioned media from an untransfected human embryonic kidney cell line, HEK-293H $(293 \mathrm{H}$ control) at $8.5 \%(\mathrm{v} / \mathrm{v})$ and $293 \mathrm{H}$-expressed GDF9 with BMP15 at 25 and $6 \mathrm{ng} / \mathrm{ml}$ respectively. These doses were based on the previously published experiments (Mclntosh et al. 2008) because they gave optimal stimulation of ${ }^{3} \mathrm{H}$-thymidine incorporation with minimal interference from the $293 \mathrm{H}$ expression media. Recombinant murine and ovine GDF9 and BMP15 were prepared and quantified as described previously (McNatty et al. 2005a, Mclntosh et al. 2008). Briefly, cDNA containing full-length sequences of each protein were sub cloned into pEFIRES-P expression vectors and transfected into $293 \mathrm{H}$ cells, and the recombinant proteins were produced in supplemented serum-free medium (DMEM/Ham's F12, 1:1). The amounts of GDF9 and BMP15 in the expression media were determined by western blot analysis under reducing conditions with monoclonal antibodies against ovine GDF9, ovine BMP15 and murine GDF9, and a polyclonal antibody against murine BMP15. The intensities of the $293 \mathrm{H}$ cell expressed GDF9 and BMP15 bands were compared with a standard curve of known concentrations of Escherichia coli (E. coli)-expressed protein. The rat granulosa cells were cultured with GDF9+BMP15 with and without inhibitors to different signalling pathways: SMAD2/3 (SB431542; $1 \mu \mathrm{M}$; Tocris, Avonmouth, UK); SMAD1/5/8 (dorsomorphin; $1 \mu \mathrm{M}$; Sigma); NFKB (SN50; $10 \mu \mathrm{g} / \mathrm{ml}$; Calbiochem, Merck); JNK (TAT-TI-JIP ${ }_{153-163} ; 5$ MM; Calbiochem); p38-MAPK (SB239063; $5 \mu \mathrm{M}$; Tocris) and; ERK-MAPK (U0126; $5 \mu \mathrm{M}$; Calbiochem). SB431542 inhibits TGFB1, ACVR1B and ACVR1C receptor signalling via SMAD2/3 whereas dorsomorphin inhibits ACVR1, BMPR1A and BMPR1B receptor signalling via SMAD1/5/8. Inhibitors were added to the wells with the treatments prior to addition of the granulosa cells. SN50 was 
stable for up to 6 months at $-70{ }^{\circ} \mathrm{C}$ after reconstitution, whereas all other inhibitors were either used fresh or stored at $-70{ }^{\circ} \mathrm{C}$ and used within 2 weeks of reconstitution. The effects of these inhibitors were also tested on untreated granulosa cells and cells treated with human activin A $(10 \mathrm{ng} / \mathrm{ml} ; \mathrm{R} \& \mathrm{D}$ Systems, Pharmaco, Auckland, New Zealand), human BMP4 (30 ng/ml; R\&D Systems) and FCS 5\% v/v (Invitrogen), all of which were included as controls. All wells contained a total of $8.5 \%(\mathrm{v} / \mathrm{v}) 293 \mathrm{H}$-conditioned media as the GDF9 and BMP15 solutions were unpurified preparations of $293 \mathrm{H}$ expression media and this causes some inhibition of ${ }^{3} \mathrm{H}$-thymidine incorporation in granulosa cells. A DMSO vehicle control was also added to the treatments as the inhibitors were reconstituted in DMSO. Treatments were performed in quadruplicate wells with a minimum of three independent pools of granulosa cells and two independent bioassays. The doses of inhibitors used for these studies were based on the given ED50 of the inhibitors and from preliminary dose-response studies using the inhibitors in untreated and GDF9+BMP15-treated granulosa cells (data not shown).

\section{Determination of molecular forms of murine and ovine GDF9+BMP15}

Samples of conditioned media containing 293H-expressed murine and/or ovine GDF9 and BMP15 at 25 and $6 \mathrm{ng} / \mathrm{ml}$ respectively were run on $13.5 \%$ SDS-PAGE under reducing conditions either before or after chemical cross-linking with bis-sulphosuccinimidyl suberate (Pierce, Rockford, IL, USA). Immunoblotting was performed using standard methods with either monoclonal antibody 37A (mab37A) made against fulllength $E$. coli-produced ovine GDF9 mature protein (McIntosh et al. 2008), mab61A produced against full-length E. coliproduced ovine BMP15 (McNatty et al. 2005a) or mab3A-A made against a 29 mer peptide sequence from the C-terminal end of human BMP15 in the same manner as has previously been described (Juengel et al. 2002). Chemiluminescent detection was used to visualise the bands.

\section{Statistical analysis}

The mean count for each set of quadruplicate wells was log transformed and, as treatment allocation was not balanced across plates, analysed by residual maximum likelihood (Patterson \& Thompson 1971) with plate within granulosa cell pool within date as random effects and DMSO concentration plus treatment (the factorial interaction of inhibitory and stimulatory treatments) as fixed effects. It was established that there was no significant effect of DMSO concentration at the control level of stimulatory treatment $(P>0.05)$. Standard errors were calculated using the Taylor's series approximation for the variance of a function.

\section{Declaration of interest}

AgResearch holds patents related to the use of BMP15 and GDF9 in regulating ovarian function. J Juengel and K McNatty are listed as inventors on these patents however both have assigned their ownership to AgResearch Ltd.

\section{Funding}

Funding support was received from the New Zealand Foundation for Research, Science and Technology (grant numbers: C10X0308 and C10X0810) and a Royal Society of New Zealand Marsden grant (08-VUW-010 CMP).

\section{Acknowledgements}

We thank Mika Laitinen and Olli Ritvos for providing the ovine BMP15- and GDF9-transfected 293H cells; Nigel Groome for supplying the monoclonal antibodies and Michael Beaumont, Shirley Martin, Taryn Skinner and Alexia Kauff for assistance with the granulosa cell bioassays.

\section{References}

Atfi A, Djelloul S, Chastre E, Davis R \& Gespach C 1997 Evidence for a role of Rho-like GTPases and stress-activated protein kinase/c-Jun N-terminal kinase (SAPK/JNK) in transforming growth factor beta-mediated signaling. Journal of Biological Chemistry 272 1429-1432. (doi:10.1074/jbc. 272.40.24731)

Belville C, Jamin SP, Picard JY, Josso N \& di Clemente N 2005 Role of type I receptors for anti-Mullerian hormone in the SMAT-1 Sertoli cell line. Oncogene 24 4984-4992. (doi:10.1038/sj.onc.1208686)

Compton LA, Potash DA, Mundell NA \& Barnett JV 2006 Transforming growth factor-beta induces loss of epithelial character and smooth muscle cell differentiation in epicardial cells. Developmental Dynamics 235 82-93. (doi:10.1002/dvdy.20629)

Di Pasquale E \& Brivanlou AH 2009 Bone morphogenetic protein 15 (BMP15) acts as a BMP and Wnt inhibitor during early embryogenesis. Journal of Biological Chemistry 284 26127-26136. (doi:10.1074/jbc. M109.036608)

Dong J, Albertini DF, Nishimori K, Kumar TR, Lu N \& Matzuk MM 1996 Growth differentiation factor-9 is required during early ovarian folliculogenesis. Nature 383 531-535. (doi:10.1038/383531a0)

Dorrington J, Chuma AV \& Bendell JJ 1988 Transforming growth factor \{beta\} and follicle-stimulating hormone promote rat granulosa cell proliferation. Endocrinology 123 353-359. (doi:10.1210/endo123-1-353)

Edwards SJ, Reader KL, Lun S, Western A, Lawrence S, McNatty KP \& Juengel JL 2008 The cooperative effect of growth and differentiation factor-9 and bone morphogenetic protein (BMP)-15 on granulosa cell function is modulated primarily through BMP receptor II. Endocrinology 149 1026-1030. (doi:10.1210/en.2007-1328)

Erickson GF \& Shimasaki S 2003 The spatiotemporal expression pattern of the bone morphogenetic protein family in rat ovary cell types during the estrous cycle. Reproductive Biology and Endocrinology 1 9. (doi:10. 1186/1477-7827-1-9)

Feary ES, Juengel JL, Smith P, French MC, O'Connell AR, Lawrence SB, Galloway SM, Davis GH \& McNatty KP 2007 Patterns of expression of messenger RNAs encoding GDF9, BMP15, TGFBR1, BMPR1B, and BMPR2 during follicular development and characterization of ovarian follicular populations in ewes carrying the Woodlands FecX2W mutation. Biology of Reproduction 77 990-998. (doi:10.1095/biolreprod.107.062752)

Galloway SM, McNatty KP, Cambridge LM, Laitinen MP, Juengel JL, Jokiranta TS, McLaren RJ, Luiro K, Dodds KG, Montgomery GW et al. 2000 Mutations in an oocyte-derived growth factor gene (BMP15) cause increased ovulation rate and infertility in a dosage-sensitive manner. Nature Genetics 25 279-283. (doi:10.1038/77033)

Gilchrist RB, Ritter LJ, Myllymaa S, Kaivo-Oja N, Dragovic RA, Hickey TE, Ritvos O \& Mottershead DG 2006 Molecular basis of oocyte-paracrine signalling that promotes granulosa cell proliferation. Journal of Cell Science 119 3811-3821. (doi:10.1242/jcs.03105)

Gueripel X, Benahmed M \& Gougeon A 2004 Sequential gonadotropin treatment of immature mice leads to amplification of transforming 
growth factor beta action, via upregulation of receptor-type 1, SMAD2 and 4, and downregulation of Smad 6. Biology of Reproduction 70 640-648. (doi:10.1095/biolreprod.103.021162)

Hanrahan JP, Gregan SM, Mulsant P, Mullen M, Davis GH, Powell R \& Galloway SM 2004 Mutations in the genes for oocyte-derived growth factors GDF9 and BMP15 are associated with both increased ovulation rate and sterility in Cambridge and Belclare sheep (Ovis aries). Biology of Reproduction 70 900-909. (doi:10.1095/biolreprod.103.023093)

Hoshiya Y, Gupta V, Segev DL, Hoshiya M, Carey JL, Sasur LM, Tran TT, Ha TU \& Maheswaran S 2003 Mullerian inhibiting substance induces $\mathrm{NF \kappa B}$ signaling in breast and prostate cancer cells. Molecular and Cellular Endocrinology 211 43-49. (doi:10.1016/j.mce.2003.09.010)

Juengel JL, Hudson NL, Heath DA, Smith P, Reader KL, Lawrence SB, O'Connell AR, Laitinen MP, Cranfield M, Groome NP et al. 2002 Growth differentiation factor 9 and bone morphogenetic protein 15 are essential for ovarian follicular development in sheep. Biology of Reproduction 67 1777-1789. (doi:10.1095/biolreprod.102.007146)

Kaivo-Oja N, Bondestam J, Kamarainen M, Koskimies J, Vitt U, Cranfield M, Vuojolainen K, Kallio JP, Olkkonen VM, Hayashi $M$ et al. 2003 Growth differentiation factor-9 induces SMAD2 activation and Inhibin B production in cultured human granulosa-Luteal cells. Journal of Clinical Endocrinology and Metabolism 88 755-762. (doi:10.1210/jc.2002-021317)

Lin A 2003 Activation of the JNK signaling pathway: breaking the brake on apoptosis. BioEssays 25 17-24. (doi:10.1002/bies.10204)

Lu T \& Stark GR 2004 Cytokine overexpression and constitutive NFKB in cancer. Cell Cycle 3 1114-1117. (doi:10.4161/cc.3.9.1130)

Mazerbourg S, Klein C, Roh J, Kaivo-Oja N, Mottershead DG, Korchynskyi O, Ritvos O \& Hsueh AJ 2004 Growth differentiation factor-9 signaling is mediated by the type I receptor, activin receptor-like kinase 5. Molecular Endocrinology 18 653-665. (doi:10.1210/me.20030393)

McIntosh CJ, Lun S, Lawrence S, Western AH, McNatty KP \& Juengel JL 2008 The proregion of mouse BMP15 regulates the cooperative interactions of BMP15 and GDF9. Biology of Reproduction 79 889-896. (doi:10.1095/biolreprod.108.068163)

McNatty KP, Juengel JL, Reader KL, Lun S, Myllymaa S, Lawrence SB, Western A, Meerasahib MF, Mottershead DG, Groome NP et al. 2005 Bone morphogenetic protein 15 and growth differentiation factor 9 co-operate to regulate granulosa cell function. Reproduction 129 473-480. (doi:10.1530/rep.1.0511)

McNatty KP, Juengel JL, Reader KL, Lun S, Myllymaa S, Lawrence SB, Western A, Meerasahib MF, Mottershead DG, Groome NP et al. 2005b Bone morphogenetic protein 15 and growth differentiation factor 9 co-operate to regulate granulosa cell function in ruminants. Reproduction 129 481-487. (doi:10.1530/rep.1.00517)

Mohan RR, Kim WJ, Mohan RR, Chen L \& Wilson SE 1998 Bone morphogenic proteins 2 and 4 and their receptors in the adult human cornea. Investigative Ophthalmology \& Visual Science 39 2626-2636.

Moore RK, Otsuka F \& Shimasaki S 2003 Molecular basis of bone morphogenetic protein-15 signaling in granulosa cells. Journal of Biological Chemistry 278 304-310. (doi:10.1074/jbc.M207362200)

Moore RK, Erickson GF \& Shimasaki S 2004 Are BMP-15 and GDF-9 primary determinants of ovulation quota in mammals? Trends in Endocrinology and Metabolism 15 356-361. (doi:10.1016/j.tem.2004. 08.008)
Oklu R \& Hesketh R 2000 The latent transforming growth factor beta binding protein (LTBP) family. Biochemical Journal 3 601-610. (doi:10. 1042/0264-6021:3520601)

Patterson HD \& Thompson R 1971 Recovery of inter-block information when block sizes are unequal. Biometrika 58 545-554. (doi:10.1093/ biomet/58.3.545)

Peter AT \& Dhanasekaran N 2003 Apoptosis of granulosa cells: a review on the role of MAPK-signalling modules. Reproduction in Domestic Animals 38 209-213. (doi:10.1046/j.1439-0531.2003.00438.x)

Rosairo D, Kuyznierewicz I, Findlay J \& Drummond A 2008 Transforming growth factor-\{beta\}: its role in ovarian follicle development. Reproduction 136 799-809. (doi:10.1530/REP-08-0310)

Sano Y, Harada J, Tashiro S, Gotoh-Mandeville R, Maekawa T \& Ishii S 1999 ATF-2 is a common nuclear target of Smad and TAK1 pathways in transforming growth factor-beta signaling. Journal of Biological Chemistry 274 8949-8957. (doi:10.1074/jbc.274.13.8949)

Saragueta PE, Lanuza GM \& Baranao JL 2002 Autocrine role of transforming growth factor beta1 on rat granulosa cell proliferation. Biology of Reproduction 66 1862-1868. (doi:10.1095/biolreprod66.6. 1862)

Shimasaki S, Moore RK, Otsuka F \& Erickson GF 2004 The bone morphogenetic protein system in mammalian reproduction. Endocrine Reviews 25 72-101. (doi:10.1210/er.2003-0007)

Sieber C, Kopf J, Hiepen C \& Knaus P 2009 Recent advances in BMP receptor signaling. Cytokine \& Growth Factor Reviews 20 343-355. (doi:10.1016/j.cytogfr.2009.10.007)

Vitt UA, Hayashi M, Klein C \& Hsueh AJ 2000 Growth differentiation factor-9 stimulates proliferation but suppresses the follicle-stimulating hormone-induced differentiation of cultured granulosa cells from small antral and preovulatory rat follicles. Biology of Reproduction 62 370-377. (doi:10.1095/biolreprod62.2.370)

Vitt UA, Mazerbourg S, Klein C \& Hsueh AJ 2002 Bone morphogenetic protein receptor type II is a receptor for growth differentiation factor- 9 . Biology of Reproduction 67 473-480. (doi:10.1095/biolreprod67.2.473)

Yan C, Wang P, DeMayo J, DeMayo FJ, Elvin JA, Carino C, Prasad SV, Skinner SS, Dunbar BS, Dube JL et al. 2001 Synergistic roles of bone morphogenetic protein 15 and growth differentiation factor 9 in ovarian function. Molecular Endocrinology 15 854-866. (doi:10.1210/ me.15.6.854)

Yang P \& Roy SK 2006 Transforming growth factor B1 stimulated DNA synthesis in the granulosa cells of preantral follicles: negative interaction with epidermal growth factor. Biology of Reproduction 75 140-148. (doi:10.1095/biolreprod.105.050294)

Yi SE, LaPolt PS, Yoon BS, Chen JY, Lu JK \& Lyons KM 2001 The type I BMP receptor BmprlB is essential for female reproductive function. PNAS 98 7994-7999. (doi:10.1073/pnas.141002798)

Received 29 November 2010

First decision 14 January 2011

Revised manuscript received 1 March 2011

Accepted 7 April 2011 